\title{
Pelatihan KKM (Kepala Kamar Mesin) Bagi Nelayan di Kecamatan Kragan Kabupaten Rembang Jawa Tengah
}

\author{
Eko Wismo Winarto' ${ }^{1^{*}}$, Harjono ${ }^{2}$, Lava Himawan ${ }^{3}$ \\ 1,2Program Studi Teknologi Rekayasa Pemeliharaan Alat Berat, Departemen Teknik Mesin \\ Sekolah Vokasi, Universitas Gadjah Mada \\ 3Program Studi Teknik Sipil, Departemen Teknik Sipil, Sekolah Vokasi, UGM
}

*Email: felix_eko@ugm.ac.id

\begin{abstract}
Abstrak
Bertambahnya umur pakai Mesin diesel untuk operasi kapal akan menurunkan performanya. Beberapa permasalahan akan terjadi diantaranya : mesin tidak mudah dinyalakan, warna gas buang dan output tenaga yang buruk, mesin tiba tiba berhenti, dan mesin tidak bisa dinyalakan. Oleh karena itu diperlukan perawatan khusus untuk menjaga kestabilan performa mesin. Pelatihan untuk KKM (Kepala Kamar Mesin) diperlukan agar mereka mempunyai teknik pemeliharaan yang benar, yang selama ini pengetahuan pemeliharaan didapat dari teman sejawat atau otodidak. Peristiwa kebakaran 25 kapal nelayan di pantai Blora beberapa waktu yang lalu menunjukkan belum memadai pengetahuan dan teknik pemeliharaan mesin Diesel yang benar. Adapun perawatan rutin yang harus dilakukan adalah; tiap delapan jam pemeriksaan rutin air radiator, pelumas dan bahan bakar, tiap minggu ( 150 jam) membersihkan saringan udara, tiap tengah bulan (250 jam) mengganti minyak pelumas, tiap bulan (500 jam) penyetelan ulang klep bahan bakar, tiap 1000 jam ganti minyak pelumas dan periksa fungsi garvernor, tiap 1500 jam bersihkan inlet manifold dan sistem exhaust, tiap 3000 jam bersihkan tangki bahan bakar dan top overhaul serta ganti komponen yang mengalami keausan, tiap 6ooo jam bongkar cylinder head dan lakukan dekarbonisasi dan tiap 12000 jam lakukan general over haul dan ganti komponen komponen yang telah aus.
\end{abstract}

Kata Kunci: Mesin Diesel, KKM, Perawatan rutin, manifold, exhaust.

\begin{abstract}
The diesel engine lifespan increasing in marine operation will decrease their perfomance. Some problems will occur, there are hard starting, bad exhaust gas colour and bad power output, suddenly engine stop and hard to start back. There fore any diesel engine training is needed to guard engine perfome. The KKM (Ketua Kamar Mesin= engine room head) training for maintaining their ability to serve diesel engine properly is necesary. Their ability have came from their friend or autodidact. The 25 fishingman ships were burning at Blora quay last several mounths prove of the lack of their ability. Thre are some rutine maintenances sould be done; every 8 hours Radiator water, diesel fuel and lubricantion oil are controlled, every week (150 hours) air screen cleaning, every two weeks (250 hours) oil lubricant replacement. Every month (50o hours) readjust fuel valve, every 1000 hours oil lubricant replacement and garvernor funtion checking, every 1500 hours inlet manifold cleaning and exhaust sistem, every 3000 fuel tank cleaning and to overhaul also replacement worn out spare parts, every 6ooo hours cylinder head take apart and carbonation, and every 12000 hours general over haul and replacement worn out spare part.
\end{abstract}

Keywords: Diesel engine, KKM, rutine maintenance, manifold, exhaust. 


\section{PENDAHULUAN}

Beberapa kasus umum kerusakan mesin diesel dan cara penangulangan :

1. Kasus mesin tidak dapat dinyalakan.

a. Tuas engkol tidak dapat digerakkan atau terlalu berat untuk dinyalakan. Penyebabnya viskositas dari pelumas tidak cocok, bagian-bagian mesin saling melekat atau terlalu rapat pemasangannya. Penanggulangannya periksa viskositas, bongkar dan pasang kembali bagian-bagian mesin.

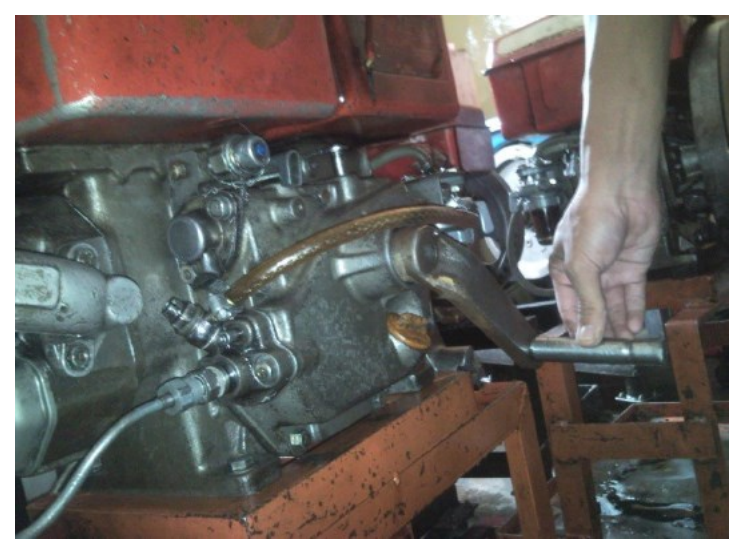

Gambar Permasalahan pada tuas engkol

b. Tuas engkol tidak dapat berputar, tapi penyalaan dapat berjalan lancar. Penyebabnya tekanan dari tangki udara terlalu kecil. Penanggulangannya: pasokan udara dari kompresor harus melebihi $20 \mathrm{~kg} / \mathrm{cm}^{2}$ dalam tangki.

c. Tuas engkol berputar tapi mesin tidak menyala, dan seperti ada kerusakan pada injeksi bahan bakar. Penyebabnya udara bercampur dengan bahan bakar (masuk angin), tertutupnya saringan bahan bakar atau pipa, kerusakan pompa injeksi bahan bakar atau kualitas bahan bakar yang buruk. Penanggulangannya: alirkan udara melalui pipa, bersihkan saringan bahan bakar, periksa pompa injeksi bahan bakar, ganti dengan bahan bakar yang berkualitas baik.

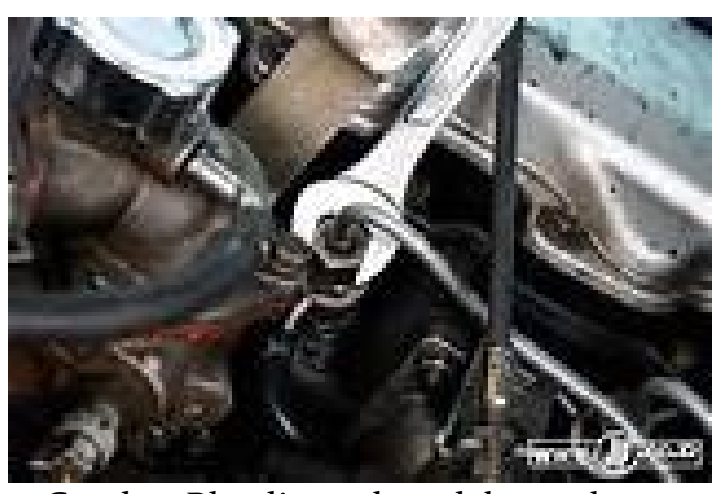

Gambar Bleeding udara dalam saluran bahan bakar

2. Kasus warna gas buang buruk dan output yang buruk.

a. Aliran gas tidak keluar dari tiap silinder. Penyebabnya temperatur aliran udara tidak tepat, buruknya kualitas pipa. Penanggulangannya: periksa dan sesuaikan temperatur, periksa tekanan dan volume dari injeksi bahan bakar.

b. Asap hitam keluar dari silinder. Penyebabnya bahan bakar tidak cocok atau mesin kelebihan beban. Penaggulangannya: bandingkan dengan jenis bahan bakar yang lain, kurangi beban ke keadaan normal.

c. Warna asap biru atau putih. Penyebabnya cincin pelumas lengket, viskositas dari minyak pelumas tidak cocok. Penanggulangannya: ganti cincin pelumas dengan yang baru, sesuaikan viskositas pelumas.

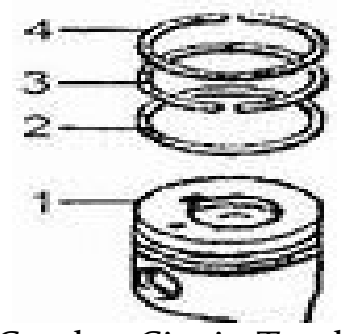

Gambar Cincin Torak

3. Mesin tiba-tiba berhenti.

Penyebabnya pasokan bahan bakar terhalang, bahan bakar habis, bahan bakar tercampur dengan udara. Penanggulangannya: bongkar dan pasang kembali bagian-bagian mesin, isi bahan bakar, dan hilangkan udara dalam bahan bakar.

4. Mesin Diesel Yang Susah di Hidupkan. 
Langkah awal yang harus anda lakukan yaitu dengan mencari penyebabnya:

a. Kompresi Mengalami Kebocoran Masalah tersebut bisa di sebabkan akibat klep atau katup yang sudah mengalami bocor, gasket atau yang sering juga di sebut dengan paking silinder head bocor, atau juga bisa ring piston dan juga boring yang sudah mengalami keausan.

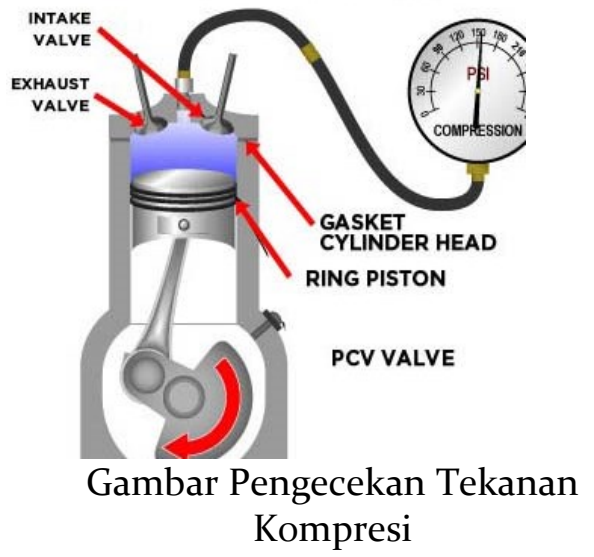

b. Nosel mengalami kerusakan

Nosel atau pengabut bahan bakar sudah mengalami kerusakan dan mengakibatkan bahan bakar tidak mengabut dengan sempurna.

c. Pompa solar Rusak

Jika komponen tersebut telah mengalami kerusakan maka akan mengakibatkan kurangnya tekanan atau malah tidak memompa solar . Jika masalah tersebut terjadi maka masin sama sekali tidak bisa hidup.

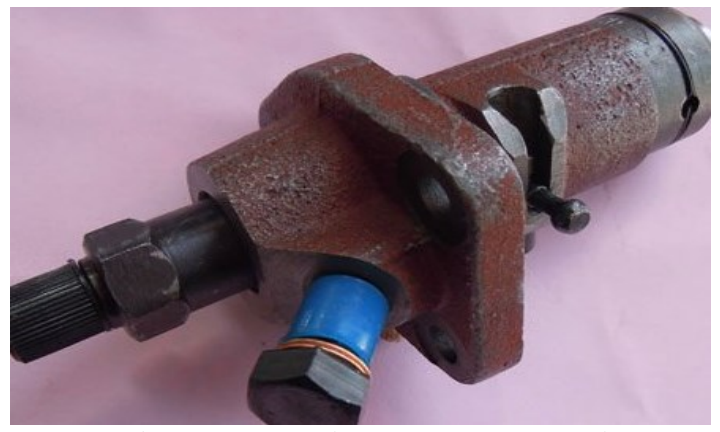

Gambar Pemeriksaan Pompa Solar

d. Kebocoran yang mengakibatkan saluran bahan bakar kosong

Mesin diesel mengandalkan busi pijar untuk membakar bahan bakar yang di kabutkan menggunakan udara panas hasil kompresi, maka dari itu jika kompresi kecil maka mesin akan susah hidup.

Pada point tiga (C) dan point empat (D) itu akan ditandai saat memutar slenger mesin maka tidak akan terdengar bunyi semprotan solar di nozzle, Bunyinya yang jika kita putar slenger akan ada bunyi "KEK"

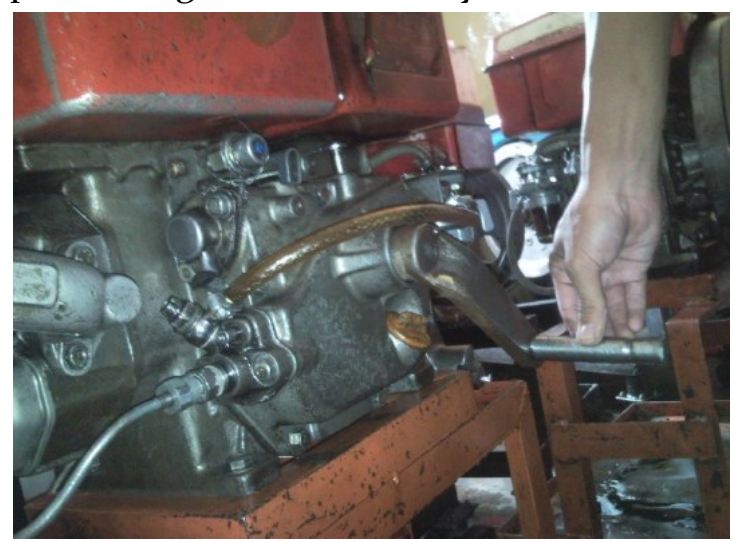

Gambar Menghidupkan Mesin Diesel

Langkah untuk menghidupkan masin diesel yang susah untuk di hidupkan: Pertama buka tutup saringan udara kemudian masukan oli mesin atau solar ke lubang manifold udara yang tutupnya sudah di buka tadi, kira - kira 1 sampai 2 tutup botol mesin. Setelah itu putar slenger atau start mesin. Jika hal tersebut masih saja belum hidup, lakukanlah langkah tadi sekali lagi .

\section{METODE}

Metode yang digunakan dalam Mencegah kerusakan yang semakin parah maka dapat dilakukan langkah perawatan seperti dibawah ini :

\section{Perawatan Mesin Diesel}

1. Tiap delapan jam (perawatan harian)

- Periksa keadaan air radiator, pelumas, bahan bakar.

- Buang air yang mungkin ada dalam saluran pembakaran.

- Periksa ikatan baut.

- Berikan sedikit pelumas pada stangstang penghubung governor.

- Bersihkan saringan udara.

Tujuannya:

- Mesin dapat digunakan tiap hari dan dapat dioperasikan dengan baik.

- Mengetahui keadaan bahan bakar, radiator dan minyak pelumas. 
- Mengetahui baut yang kendor karena getaran pada mesin diesel.

2. Pemeliharaan mingguan (150 jam)

- Membuka dan membersihkan saringan udara.

- Periksa kebocoran pada saluran minyak pelumas dan bahan bakar.

- Cuci dan bersihkan badan mesin.

Tujuannya:

- Saringan udara bersih dari debu agar tidak menghambat udara yang masuk.

- Mengetahui kebocoran pada sluran pelumas dan bahan bakar.

- Badan mesin tidak mudah terkena korosi dan karat.

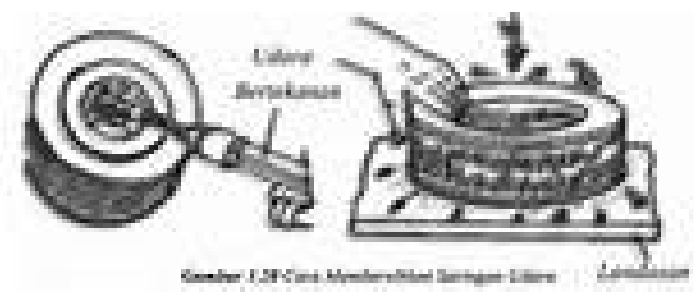

Gambar Cara membersihkan saringan udara

3. Pemeliharaan Tengah Bulanan (250 jam)

- Buang dan ganti minyak pelumas.

- Bersihkan sirip-sirip pendingin, pada mesin dengan pendingin air .

Tujuannya:

- Mengetahui kebocoran pada saluran pelumas dan bahan bakar.

- Penyalaan awal lebih mudah.

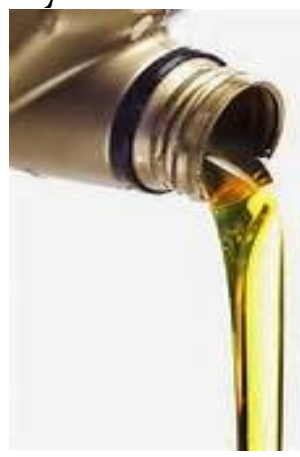

Gambar Penggunaan Oli pelumas yang sesuai

4. Pemeliharaan bulanan (50o jam)

- Periksa dan stel klep bila dianggap perlu.
- Bersihkan badan mesin dan base panel.

Tujuannya:

- Suara mesin tidak terlalu keras.

- Badan mesin dan plat tidak mudah terkena korosi.

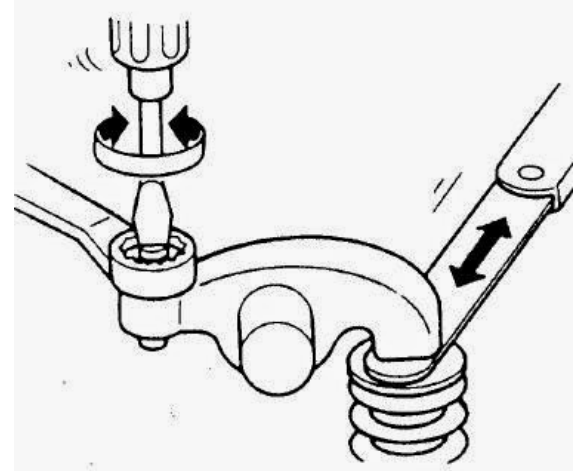

Gambar Penyetelan katup

5. Pemeliharaan 1000 jam.

- Buang, cuci, dan ganti minyak pelumas.

- Memeriksa fungsi-fungsi governor.

Tujuannya:

- Pelumasan pada mesin lebih sempurna.

- Mengetahui governor berfungsi dengan baik

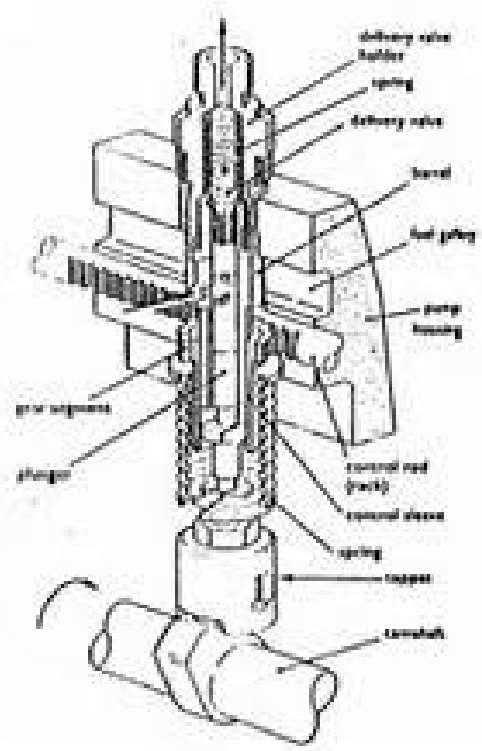

Gambar Pemeriksaan Komponen Governoor

6. Pemeliharaan 1.500 jam 
- Bersihkan inlet manifold dan sistem exhaust.

- Bersihkan sirip-sirip pendingin pada mesin dengan menggunakan air.

- Periksa stang penghubung governor dan lumasi dengan minyak pelumas

- Ganti saringan bahan bakar.

- Bersihkan nozzle dan stel tekanannya.

- Lakukan dekarbonisasi bila mesin menunjukkan gejala penurunan kompresi.

- Mengukur atau mempebaiki defleksi poros.

Tujuannya:

- Mesin dapat bekerja dengan baik dan siap digunakan sewaktu waktu.

- Dekarbonisasi bertujuan kompresi pada mesin menjadi lebih baik.

- Untuk mengetahui seberapa besar defleksi pada poros engkol.

7. Pemeliharaan 3.000 jam

- Bersihkan tangki bahan bakar.

- Bersihkan saluran air pendingin dan oil cooler.

- Lakukan Top Overhaul, ganti komponen yang mengalami kehausan.

Tujuannya:

- Badan mesin tahan lama dan tidak tekena korosi.

- Mesin dapat digunakan lebih lama.

- Top over haul adalah untuk mengetahui komponen mana saja yang harus diganti dan yang masih bisa dipakai.

8. Pemeliharaan 6.ooo jam

- Periksa pegas katup.

- Bongkar cylinder head dan lakukan dekarbonisasi.

- Bersihkan rongga-rongga air pendingin.

- Bersihkan kerak-kerak pada permukaan piston.

- Bersihkan seluruh sistem exhaust.

- Bersihkan pipa-pipa saluran bahan bakar.

- Periksa dan bersihkan pipa-pipa minyak pelumas.
Tujuannya:

- Mesin dapat digunakan lebih baik.

- Tidak tersumbat oleh debu dan kotoran.

- Untuk mengetahui bagian mana saja yang perlu diganti.

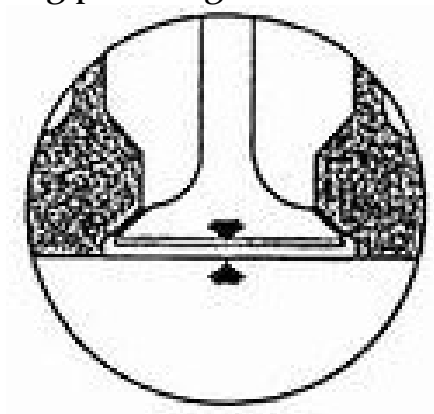

Gambar Pemeriksaan Pegas Katup

9. Pemeliharaan 12.000 jam

- Lakukan general over haul, ganti komponen-komponen yang mengalami keausan.

- Pemeriksaan atau ganti piston klep.

- Pemeriksaan atau ganti pompa injeksi.

- Pemeriksaan atau ganti klep (katup).

Tujuannya:

- Mesin tahan lama

- General ovehaul untuk mengganti komponen yang mengalami keausan.

\section{HASIL DAN PEMBAHASAN}

Dari pelatihan yang telah dilakukan diketahui bahwa banyak dari KKM nelayan yang belum tahu dan bahkan melakukan kesalahan dalam perawatan mesin diesel, maka banyak dari mereka menyambut pelatihan ini dengan antusias yaitu dibuktikan dengan banyaknya peserta yang hadir untuk mengikuti pelatihan perawatan mesin diesel ini. Dari pendapat mereka ternyata pengetahuan yang dimiliki didapat dari sesama nelayan yang lebih berpengalaman dan juga dari penjual mesin diesel tersebut. Dengan diadakan pelatihan ini diharapkan nelayan mampu menjadwal aktifitas yang harus dilakukan guna merawat mesin diesel dengan benar, sehingga dapat memperpanjang umur mesin maupun mengurangi pengeluaran 
untuk penggantian sparepart mesin diesel. Dari seluruh pelatihan ini dapat meningkatkan penghasilan nelayan karena tidak mengalami kerusakan mesin diesel dan dapat mengoptimalkan kerja mesin diesel mereka dan akhirnya akan meningkatkan pendapatan mereka.

\section{SIMPULAN}

Pelatihan semacam ini sangat diperlukan nelayan untuk meningkatkan pengetahuan mereka terhadap perawatan mesin diesel dan pada akhirnya dapat meningktkan pendapatan mereka.

\section{DAFTAR PUSTAKA}

Anonim, Sistem Bahan bakar Motor Diesel dengan Pompa in-Line di ambil dari alamat web http:/2. Bp.blogspot.com/y9LynPEu8Y/VfEL8kT7sel/A

AAAAAAAAdo/Lpp2dYKAV8/s16oo/B agian\%2Bsistem\%2Bbakar\%Bdiesel\%2 Bdengan\%2Bpompa\%2Binline.png.

Diakses pada hari rabu, Tanggal 191 Juli 2017 pukul 13:28.

Arifin, Zainal, Sukoco, (2009), Pengendalian Polusi Kendaraan, Alfabeta, Bandung

Arismunandar, Wiranto, dan Koichi Tsuda, (2008), Motor diesel Putaran Tinggi, P.T. Pradnya Paramita, Jakarta.

Aug, 1988, Engine Repair Manual ToyotaB, 3B, $11 \mathrm{~B}, 14 \mathrm{~B}$. 